ANTOLOGIA Trans. 30 poetas trans, travestis e não-binários. São Paulo: Invisíveis Produções, 2017.

\title{
A DOR DO COMPASSO DE TODAS AS RIMAS
}

\author{
Luiz Henrique Moreira Soares ${ }^{1}$ \\ Adenize Aparecida Franco ${ }^{2}$
}

Por trás de toda escrita há um corpo-vivo. E a escrita atravessa esse corpo-vivo - corpo que anda pelas ruas, calçadas, pelos palcos, pelos espaços indizíveis e incomunicáveis, pelos silêncios gritados de vidas que não cabem no papel. Corpos que escrevem. Escrevem palavras tortas, escrevem o existir, verbo intransitivo. Na estrada do céu da boca, boca cheia de coisas para se dizer, histórias e vidas, há a dor (e a delícia) do compasso de todas as rimas: "Que palavras conseguem cantar o que sai do coração?", pergunta um dos versos do poema "Uma exclamação", já na página 32. É que os sons e as palavras são navalhas, e a escrita - esse ato performativo de liberdade e de deslocamento cria pontes de conexão, união e resistência, restaura as possibilidades de articular poderes.

Com prefácio da escritora e prostituta Amara Moira, com ilustrações de Augusto Silva e Lune Carvalho, a obra Antologia trans (Invisíveis Produções, 2017), não passou despercebida nos lançamentos literários do ano de 2017. Ao todo, a antologia comporta trinta poetas e poetisas travestis, transexuais e não-binários, apresentando quarenta e quatro textos, produzidos durante as oficinas de poesia do Cursinho Popular Transformação, em São Paulo. O livro conta, ainda, com a participação de outros dezessete artistas convidados. Lançada durante o TRANSarau, realizado no mês de março de 2017, na cidade de São Paulo, a obra traz 62 poemas sobre vivências, dores e amores de pessoas trans, travestis e não binários. Pessoas que veem suas vidas serem atravessadas pelas violências, pelos

\footnotetext{
${ }^{1}$ Mestrando em Letras pelo Programa de Pós-graduação em Letras (PPGL), da Universidade Estadual Paulista "Júlio de Mesquita Filho" (UNESP) - Campus de São José do Rio Preto. Bolsista do Conselho Nacional de Desenvolvimento Científico e Tecnológico (CNPq).

${ }^{2}$ Docente do Programa de Pós-graduação em Letras da Universidade Estadual do Centro Oeste (UNICENTRO). Doutora em Estudos Comparados de Literaturas de Língua Portuguesa pela Universidade de São Paulo (USP).
} 
preconceitos, exclusões e transgressões. É por meio do poder que emana da palavra e que constrói os discursos que a Antologia trans se constitui. A obra é, em seu conjunto, um corpo literário vibrante, corpo que grita, que tenta se livrar do sufoco - que usa a linguagem na sua capacidade de desafogar e desatar os nós apertados da história. E rejeita. Rejeita representações dicotômicas e papeis secundários que não contemplam suas vidas. Rejeitam os discursos históricos que constroem expressões negativas sobre seus corpos e vivências.

É no emaranhado da linguagem que revigora, assim, a resistência da luta. A palavra "resistência" parece ecoar da primeira até a última página do livro, nas ilustrações, no corpo editorial, linguiístico e transitório que se constrói. Os textos, como afirma Linn Quebrada, na orelha do livro, são escritos de "mãos dadas", "unhas molhadas de esmalte roxo", "tapas e fantasmas". "É preciso estar atento e forte", grita o poema "Vida sem título", de autoria coletiva: o regurgitar contemporâneo e ressignificado a partir da deglutição antropofágica do Divino maravilhoso (1969), de Gilberto Gil e Caetano Veloso em seus versos pela liberdade. Escrever é um ato de liberdade. A literatura é liberdade, já dizia Sontag. Escrever é também exorcizar os fantasmas, salvar os seus e as suas.

Ao refletir sobre as perspectivas da cultura contemporânea e o processo de escrita, o crítico Silviano Santiago, em seu ensaio A prosa literária atual no Brasil (2002), afirma que “o corpo é o lugar da descoberta do ser (...) o corpo é o lugar da liberdade, de onde sai o grito do indivíduo contra as sociedades repressivas" (SANTIAGO, 2002, p. 32). O que o crítico aponta é que a palavra parece ter certa força de propor a possibilidade do domínio de si, como intervenção subversiva.

Nesse sentido, há um corpo-vivo por detrás de toda a escrita uma escrita que ficcionaliza o leitor e com ele troca saberes, processo de reconstrução: ao analisarmos a maior parte das obras literárias (romances, contos) que possuem personagens travestis, por exemplo, nos deparamos com uma parcela ínfima de espaços de representação dos corpos abjetos e desviantes das normas de gênero - e pouco espaço de enunciação própria, ou seja, expressão literária e artística que proponha novas perspectivas. O que há é uma hierarquização dos espaços sociais, que dimensionam a produção dessas representações e constroem discursos hegemônicos; discursos que colonizam os corpos e as subjetividades. $\mathrm{O}$ espaço da literatura é, sem dúvida, um espaço primordialmente regido por disputas e ela não 
está longe das noções e relações de poder que permeiam a sociedade, como bem apontado por Regina Dalcastagné, em seu Literatura brasileira contemporânea: um território contestado (2012).

Em muitos dos poemas presentes na coletânea, percebe-se a indagação e o desconforto com a estratificação das hegemonias produzidas. No poema "Inferno cotidiano", de autoria coletiva, por exemplo, há o viés político, que denota os tempos atuais e os problemas enfrentados na atual política brasileira, tal como as relações violentas de gênero, a discriminação, o crescimento do "conservadorismo doentio", a busca pela representatividade e a luta de interesses:

\author{
Estou vivendo \\ Um inferno cotidiano. \\ DESEMBARQUE PELA ESQUERDA. \\ No deserto sereno \\ Espanto-me com os avessos \\ Como avalanches de inverno \\ (um bom lugar pra ler um livro) \\ Cair pesado em palavras tortas \\ GOLPE GOLPE GOL. \\ (ANTOLOGIA Trans, 2017, p. 21).
}

Outros textos da coletânea narram histórias de violências e abusos sofridos no corpo de seus autores. Como exemplo, temos o texto "Andávamos eu e ela", de Augusto Silva, que demonstra a escuridão das (sobre)vivências nas ruas e calçadas de um mundo proibido e coberto pela incerteza da morte e da vida. Luan Bressanini, em seu poema "Eu existo", grita com todas as letras a sua luta: "a esperança é um índice de 35 anos" (ANTOLOGIA Trans, 2017, p. 87). Nesse sentido, a autora destaca (e relembra) que, no Brasil, a expectativa de vida de travestis e transexuais é de 35 anos, menos da metade da média nacional, que é de 75 anos. Segundo pesquisa do Grupo Gay da Bahia, o Brasil é o país que mais mata travestis e transexuais no mundo. Só em 2016 foram registrados 127 casos de assassinatos, um a cada 3 dias. Um dos últimos casos, fortemente divulgado pela mídia, foi a história da travesti Dandara dos Santos, que foi espancada e assassinada por um grupo de jovens num bairro da periferia de Fortaleza, no Ceará, no dia 15 de fevereiro de 2017, em plena luz do dia. E isso 
prova a vulgarização da violência e a estruturação da barbárie em nossa época, também mediadas pelo texto literário.

Por isso, pensar os direitos humanos não é apenas reconhecer o que é indispensável para nós, mas é, também, levar em consideração o que é indispensável ao outro, como observa Antonio Candido, em seu texto $O$ direito à literatura, de 1988. Nesse famoso ensaio, o crítico reconhece e a afirma a literatura como um direito básico de todo ser humano, que, agindo sob o caráter de um "instrumento poderoso de instrução e educação" e de um "equipamento intelectual e afetivo", a literatura confirma e nega, propõe e denuncia, apoia e combate, fornecendo a possibilidade de vivermos dialeticamente os problemas. Por meio das palavras, a literatura capacita a si mesmo às subversões de ordens dominantes e cria possibilidades de negação de discursos alheios.

Os poemas da Antologia trans, nesse sentido, criam a possibilidade de outros corpos poderem existir na dissidência. São poemas que saíram diretamente das "tetas indesejadas", da "ausência de pelo e falo", da "voz aguda" e da "baixa estatura", de Teodoro Albuquerque. Saíram diretamente da luta de Lucifer Ekant, que nega a escuridão do banheiro e o discurso violento de que "bixa é depósito de porra". Saíram diretamente da "Nordestinidade trans", de Dodi Leal e de todas as mulheres trans que nascem no Piauí e morrem no mundo. Esses textos saíram dos rabiscos, rascunhos e desenhos de Bernardo Enoch Mota e sua "eterna busca por buscar por toda a eternidade". Saíram também dos conselhos da Alexxa Araújo, das risadas e dos cortes de Wictor Ferreira, do silêncio alquimista de Samantha Andrade, da travestilidade comunista de Ika Eloah, da certeza de que o pássaro nasceu livre, e que o futuro é mais do que primitivo: "um a menos quando nasce, um a mais quando morre".

Portanto, os textos que compõem a primeira Antologia Trans são propostas de resistência como possibilidade histórica: há a abertura para a construção de perspectivas particulares, e, ao mesmo tempo, coletivas. Rompem e degeneram os jogos de opressão, concretizam um trabalho e um compromisso estético, ético e político com a linguagem, fazem sobreviver e (re)afirmar a existência de corpos discursivamente construídos por meio da escrita, além de (re)criar novos modos de existência no texto e para além dele.

A importância dessa antologia, portanto, reside na preocupação de tomar a escrita como um ato de poder e liberdade, uma afirmação soberana que se estabelece em uma relação 
de igualdade com o mundo. A construção de novas significações, investindo na alteridade e na assunção política do eu, só é possível a partir de vozes literárias que ecoem novas melodias, novas perspectivas. Uma Antologia trans que se configura como possibilidade dissidente de ouvir, ver e sentir outros corpos - corpos que caem, que se levantam e se exaltam na beleza da incompletude, batendo a poeira da roupa (e das palavras), sem vacilar.

\section{Referências:}

AYER, Flávia; BOTTREL, Fred. Brasil é país que mais mata travestis e transexuais. 2017. Disponível em: <https://www.em.com.br/app/noticia/especiais/dandara/2017/03/09/noticiaespecial-dandara,852965/brasil-e-pais-que-mais-mata-travestis-e-transexuais.shtml>. Acesso em: 30 abr. 2018.

CANDIDO, Antonio. O direito à Literatura. In: Vários escritos. São Paulo: Duas Cidades, 1995.

SANTIAGO, Silviano. A prosa literária atual no Brasil. In: Nas malhas da letra: ensaios. Rio de Janeiro: Rocco, 2002.

VELOSO, Caetano. Literatura Comentada. Textos comentados por Paulo Franchetti e Alcyr Pécora. São Paulo: Abril Educação, 1981. 